\title{
The application of wide-field laser ophthalmoscopy in fundus examination before myopic refractive surgery
}

Lin Liu, Fang Wang, Ding Xu, Chunlei Xie and Jun Zou*

\begin{abstract}
Background: To evaluate wide-field laser ophthalmoscopy (Optomap 200Tx) for screening retinal lesions before myopic refractive surgery.

Methods: Seventy-eight eyes of 78 consecutive refractive surgery candidates were included in this study. All subjects underwent Optomap 200Tx, mydriatic slit-lamp lens examination and the Goldmann three-mirror contact lens examination, which was considered as the reference method for determining retinal lesions.

Results: Forty of 78 eyes had retinal lesions (51.28\%) and three eyes had retinal breaks (3.85\%), which were diagnosed by the Goldmann three-mirror contact lens examination. Compared to the Goldmann three-mirror contact lens examination, the detection rate with the Optomap 200Tx was 91.73\%\% for retinal lesions, while the detection rate of mydriatic slit-lamp lens exams was $81.20 \%$. There were no statistically significant differences among the three methods used for the diagnoses of myopic conus, tessellation and retinal breaks(all $p>0.05$ ). For peripheral retinal lesions, the detection rate of the Optomap 200Tx examinations were similar to the Goldmann three-mirror contact lens exams (all $p>0.05$ ), but were higher than the results of slit-lamp lens examinations (all $p<0.05$ ). Regarding the vitreoretinal adhesions, the Goldmann three-mirror contact lens examinations had higher detection rates than did the Optomap 200Tx examinations ( $p=0.031$ ).

Conclusions: The Optomap 200Tx examinations is a convenient and feasible method to determine fundus pathological changes in myopic patients, especially for patients who can not endure pupil dilation. In order to avoid misdiagnosis of peripheral retinal lesions, Goldmann three-mirror contact lens examination is needed.
\end{abstract}

Keywords: Wide-field laser ophthalmoscope, Refractive surgery, Optomap panoramic 200Tx

\section{Background}

Myopia is the most common type of refractive error. The prevalence of myopia has continued to increase, especially in Asian countries [1,2]. Laser refractive surgery has been performed for decades. There have been tremendous advancements in terms of technique and technology, making laser refractive surgery increasingly precise and highly predictable, and laser in situ keratomileusis (LASIK) has become increasingly popular for the treatment of myopia over the past decades [3, 4].

With increased axial elongation, myopia may lead to peripheral retinal lesions, such as retinal breaks,

\footnotetext{
*Correspondence: zoujun70@126.com

Department of Ophthalmology, Shanghai Tenth People's Hospital, Tong Ji University, Shanghai 200072, China
}

(c) The Author(s). 2017 Open Access This article is distributed under the terms of the Creative Commons Attribution 4.0 International License (http://creativecommons.org/licenses/by/4.0/), which permits unrestricted use, distribution, and reproduction in any medium, provided you give appropriate credit to the original author(s) and the source, provide a link to the Creative Commons license, and indicate if changes were made. The Creative Commons Public Domain Dedication waiver (http://creativecommons.org/publicdomain/zero/1.0/) applies to the data made available in this article, unless otherwise stated. tary degeneration, lattice degeneration, posterior staphyloma, and white without pressure symptoms [5]. The association of myopic LASIK with rhegmatogenous retinal detachment (RRD) remains controversial and the frequency of RRD after LASIK was reported to be $0.06 \%$ to $0.25 \%$ [6-8]. The lattice degeneration, a risk factor for retinal breaks, may not progress into RRD by prophylactic laser photocoagulation before the refractive surgery. PostLASIK RRD usually occurs in eyes with complex retinal breaks $[9,10]$. Therefore, before the refractive surgery, a thorough retinal examination is very important.

The purpose of this study was to compare the diagnostic properties of the non-mydriatic Optomap ultra-widefield scanning laser ophthalmoscope (SLO) with the 
mydriatic slit-lamp lens [90 diopters (D)] and the Goldmann three-mirror contact lens examination for myopic screening.

\section{Methods \\ Subjects}

Seventy-eight eyes of 78 consecutive refractive surgery candidates were recruited for the study. The median age was 26 years (range, 21-39 years). The average spherical equivalent (SE) was $-5.50 \mathrm{D}$ (SD, $3.00 \mathrm{D}$ with a range of $-1.0 \mathrm{D}$ to $-10.75 \mathrm{D}$ ), and the axial length was $24.47-28.49 \mathrm{~mm}$ (average, $25.68 \pm 2.10 \mathrm{~mm}$ ). None had a history of ocular surgery, ocular trauma, or systemic or ocular health abnormality. The study was approved by the Ethics Committee of the Shanghai Tenth People's Hospital, and written informed consent was obtained by all the patients in this study.

Each subject underwent a complete ophthalmology examination, which included measurements of visual acuity, refraction, and intraocular pressure (IOP) by a noncontact tonometer. Axial length measurements were obtained in each eye with the IOL Master (Carl Zeiss Meditec, Inc., Dublin, CA, USA) and by stereoscopic fundus examination. The stereoscopic fundus examination was performed by three retinal specialists using ultra-wide-field scanning laser ophthalmoscopy (Optomap 200Tx ${ }^{\mathrm{min}}$, Optos ${ }^{\circ}$, Marlborough, MA, USA), mydriatic slit-lamp biomicroscopy (90 D lens), and a mydriatic Goldmann three-mirror contact lens. The three retinal specialists were blinded to the clinical data.

\section{Optomap imaging}

The Optomap Panoramic 200Tx device is a SLO with two scanning laser wavelengths of green $(532 \mathrm{~nm})$ and red $(633 \mathrm{~nm})$. Optomap imaging was performed without pupil dilation. Several images were taken and the best image of each eye was saved for grading. It took $0.25 \mathrm{~s}$ to obtain one image by SLO. The total scanning time was 3-5 min, including patient positioning. All Optomap imaging was performed by the same clinician, the four directions (Temporal, Nasal, Superior and Inferior) guiding and normotopia for each eye have been photographed and recorded.

\section{Statistical analysis}

Statistical analyses were performed with commercially available software (SPSS, version 15.0; SPSS Inc., Chicago, IL, USA). The results of the three types of fundus examinations were compared by the paired chisquare test. A $p$ value $<0.05$ was considered statistically significant.

\section{Results}

Goldmann three-mirror contact lens examination

Forty of 78 eyes had retinal lesions (51.28\%), which were diagnosed by the Goldmann three-mirror contact lens examination. Twenty eyes (25.64\%) were detected with myopic conus in 78 eyes, twenty-four eyes $(30.77 \%)$ had varying degrees of tessellation, thirty-four eyes (43.59\%) had white without pressure, eighteen eyes $(23.08 \%)$ had lattice degeneration, twenty-seven eyes (34.62\%) had cream sample and pigment degeneration, three eyes (3.85\%) had retinal breaks, and seven eyes (8.97\%) had vitreoretinal adhesions.

\section{Optomap 200TX imaging}

In 78 eyes of 78 myopia patients, Twenty eyes (25.64\%) were detected with myopic conus, twenty-four eyes $(30.77 \%)$ had varying degrees of tessellation, thirty-two eyes $(41.03 \%)$ had white without pressure, sixteen eyes (20.51\%) showed lattice degeneration, twenty-five eyes (32.05\%) exhibited cream sample and pigment degeneration, three eyes (3.85\%) had retinal breaks, and two eyes $(2.56 \%)$ had vitreoretinal adhesions.

\section{Mydriatic slit-lamp lens examination (90 D)}

Twenty eyes (25.64\%) were detected with myopic conusin in 78 eyes, twenty-four eyes $(30.77 \%)$ had varying degrees of tessellation, twenty-eight eyes (35.90\%) showed white without pressure, ten eyes (12.82\%) had lattice degeneration, Twenty eyes $(25.64 \%)$ had cream sample and pigment degeneration, two eyes $(2.56 \%)$ had retinal breaks, and four eyes $(5.13 \%)$ had vitreoretinal adhesions.

\section{Comparisons of the three methods}

Compared to the Goldmann three-mirror contact lens examination, the detection rate of the Optomap 200Tx for retinal lesions was $91.73 \%$ while the detection rate of the mydriatic slit-lamp lens exam was $81.20 \%$. There were no statistically significant differences among the three methods for the diagnosis of myopic conus, tessellation retinal break. For peripheral retinal lesions, the results of the Optomap 200Tx examinations were similar with the Goldmann three-mirror contact lens examinations(all $p>0.05$ ), but was better than the results of the slit-lamp lens examinations (all $p<0.05$ ). Regarding vitreoretinal adhesion detection, the Goldmann threemirror contact lens examination had a better performance than the Optomap 200Tx $(p=0.031)$. (Table 1).

\section{Discussion}

The role of LASIK as a potential additive risk factor for RRD in myopic eyes has been an issue of debate. The frequency of RRD after LASIK is reported to be $0.06 \%$ to $0.25 \%$ [6-8]. Arevalo et al. reported that the development of peripheral retinal tears or macular injury during 
Table 1 Comparisons of the three methods for detecting fundus lesions (paired chi-square test)

\begin{tabular}{|c|c|c|c|c|c|c|}
\hline & Goldman three-mirror contact lens & Optomap 200TX & mydriatic slit-lamp lens (90 D) & P1 & P2 & P3 \\
\hline myopia conus & 20 & 20 & 20 & 1.000 & 1.000 & 1.000 \\
\hline leopard fundus & 24 & 24 & 24 & 1.000 & 1.000 & 1.000 \\
\hline white without pressure & 34 & 32 & 28 & 0.727 & 0.040 & 0.031 \\
\hline lattice degeneration & 18 & 16 & 10 & 0.754 & 0.008 & 0.031 \\
\hline cream sample and pigment degeneration & 27 & 25 & 20 & 0.687 & 0.000 & 0.000 \\
\hline retinal break & 3 & 3 & 2 & 1.000 & 1.000 & 1.000 \\
\hline vitreoretinal adhesions & 7 & 2 & 4 & 0.031 & 0.375 & 0.375 \\
\hline
\end{tabular}

P1, Goldman three-mirror contact lens and Optomap 200TX; P2, Goldman three-mirror contact lens and mydriatic slit-lamp lens; P3, Optomap 200TX and mydriatic slit-lamp lens $(90 \mathrm{D}) ; P<0.05$ was statistically significant. $\mathrm{D}$, diopters

LASIK was due to vitreous traction and deformity induced by anterior-posterior compression and expansion [11-14]. Therefore, examination of the vitreous and retinal before LASIK is necessary and should be a routine procedure.

The traditional retinal examination such as the Goldmann three-mirror contact lens examination always requires pupil dilation and corneal contacting, which could be uncomfortable and have a higher risk of infection. Recently, the ultra-wide-field scanning ophthalmoscope Optomap 200Tx has become commercially available. This device uses an ellipsoid mirror and can acquire a wide-field image of the fundus, with the Optomap 200Tx imaging system. It is now possible to scan 200 degree of the retina in a single photograph without pupil dilation and corneal contacting. This can provide a much larger image of the peripheral retina than the traditional Optomap 200 [15]. With the SLO, sharp images with high contrast are obtained and can be saved permanently. The Optomap 200Tx is widely accepted and be valuable for the evaluation of several retinal pathologies, including diabetic retinopathy, retinitis pigmentosa, uveitis, age-related macular degeneration and retinal detachment [16-22].

Diagnostic imaging probably has become a significant supplement of traditional slit-lamp examination. Mackenzie et al. used the Optomap Panoramic 200 wide-field confocal scanning laser imaging system for detecting peripheral retinal lesions and found that the Optomap showed high specificity and moderate sensitivity for lesions posterior to the equator [21]. In current study, forty eyes $(51.28 \%)$ of 78 eyes with retinal lesions and three eyes with retinal breaks (3.85\%) were diagnosed by the Goldmann three-mirror contact lens examination. With the informed consent of patients, three patients who had retinal breaks underwent prophylactic laser photocoagulation to seal the breaks, even though they were asymptomatic. One of the three patients, who was peripheral retinal break with shallow detachment (Fig. 1), was performed advanced corneal surface ablation and the others were performed LASIK at least
2 weeks post-photocoagulation. The retinal detachment has not been occurred since the follow-up in this study. Compared with the Goldmann three-mirror contact lens examination, the detection rate of the Optomap 200Tx for retinal lesions was $91.73 \%$, while the detection rate of the mydriatic slit-lamp lens examination was $81.20 \%$.

In this study, higher detection rates were shown in the vitreoretinal adhesions in the Goldmann threemirror contact lens examination compared with the Optomap 200Tx examination. Possible explanations are as the followings: Firstly, the stereoscopic sensing of the Optomap 200Tx for screening of retinal diseases was not as good as that of the Goldmann three-mirror contact lens examination. Moreover, the Optomap 200Tx provided a less real color image using two monochromatic red and green SLO scans that could be viewed separately or superimposed, resulting in a semi realistic bicolor Optomap fundus image.

In practical terms, it is more important to analyze the inconsistent results between the Goldmann three-mirror contact lens examination and the Optomap 200Tx. We found that the detection numbers of the peripheral retinal lesions using the Optomap 200Tx, such as the cream sample and pigment degeneration, seemed to be

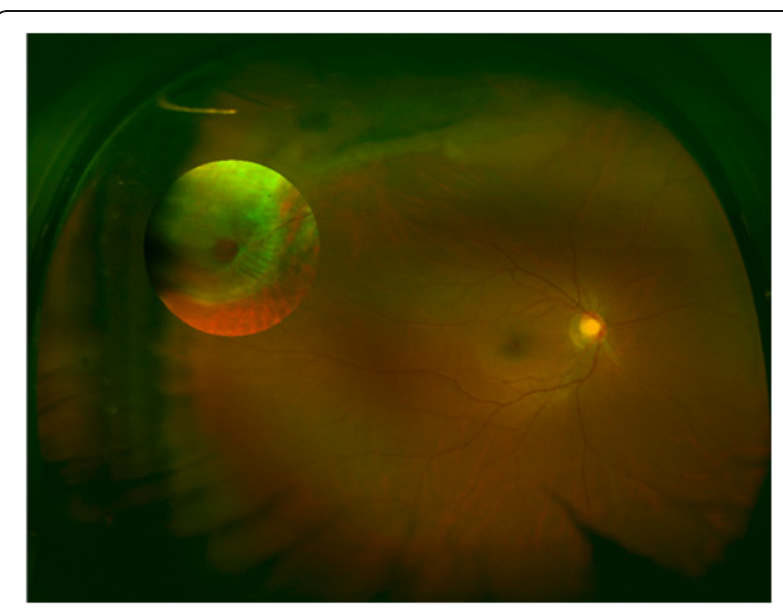

Fig. 1 Peripheral retinal break with shallow detachment in myopia 
less than with the Goldmann three-mirror contact lens examination, although no statistical significance was reached. We suggest that this was mainly due to the examination being restricted by the eyelids and eyelashes, particularly for patients with hollow eyeballs and small palpebral fissures. These may lead to a smaller angle of view in the vertical direction. Therefore, for patients with hollow eyeballs and small palpebral fissures, the Goldmann three-mirror contact lens examination may be have some advantages.

\section{Conclusions}

In conclusion, the Optomap 200Tx examinations is a convenient and feasible method for fundus pathological changes detection in myopic patients, especially for patients who can not endure pupil dilation.

\section{Abbreviations}

AMD: Age-related macular degeneration; IOP: Intraocular pressure;

LASIK: Laser in situ keratomileusis; RRD: Rhegmatogenous retinal detachment; SLO: Scanning laser ophthalmoscope

\section{Acknowledgements}

Not applicable.

\section{Funding}

Supported by Shanghai Municipal Natural Science Foundation (NO.16ZR1426700) and Project of Shanghai Science and Technology (NO.17411950207) and the Fundamental Research Funds for the Central Universities (NO.1501219166).

\section{Availability of data and materials}

The datasets analysed during the current study available from the corresponding author on reasonable request (zoujun70@126.com).

\section{Authors' contributions}

Performed the experiments: LL, DX, CLX, JZ. Analyzed the data: LL,FW. Contributed reagents/materials/analysis tools: FW, JZ. Wrote the manuscript: $\mathrm{LL}$. Contributed to the data analysis and manuscript writing: LL, JZ. All authors read and approved the final manuscript.

\section{Ethics approval and consent to participate}

The study was approved by the Ethics Committee of the Shanghai Tenth People's Hospital, and was performed according to the tenets of the Declaration of Helsinki.Written consent was obtained from all participants.

\section{Consent for publication}

Written informed consent was obtained from the patient for publication of this study and any accompanying images.

\section{Competing interests}

The authors declare that they have no competing interests.

\section{Publisher's Note}

Springer Nature remains neutral with regard to jurisdictional claims in published maps and institutional affiliations.

Received: 17 September 2016 Accepted: 4 December 2017

Published online: 15 December 2017

\section{References}

1. Dayan YB, Levin A, Morad Y, Grotto I, Ben-David R, Goldberg A, Onn E, Avni I, Levi $Y$, Benyamini OG. The changing prevalence of myopia in young adults: a 13-year series population-based prevalence surveys. Invest Ophthalmol Vis Sci. 2005;46(8):2760-5.
2. Wong TY, Foster PJ, Hee J, Ng TP, Tielsch JM, Chew SJ, Johnson GJ, Seah SK. Prevalence and risk factors for refractive errors in adult Chinese in Singapore. Invest Ophthalmol Vis Sci. 2000;41:2486-94.

3. Sugar A, Rapuano CJ, Culbertson WW, Huang D, Varley GA, Agapitos PJ, de Luise VP, Koch DD. Laser in situ keratomileusis for myopia and astigmatism: safety and efficacy: a report by the American Academy of ophthalmology. Ophthalmology. 2002;109:175-87.

4. Lin JM, Tsai YY. Laser in situ keratomileusis for different degrees of myopia. Acta Ophthalmol Scand. 2005;83(1):40-5.

5. Saw SM, Gazzard G, Shih-Yen EC, Chua WH. Myopia and associated pathological complications. Ophthalmic Physiol Opt. 2005;25(5):381-91.

6. Arevalo JF, Lasave AF, Torres F, Suarez E. Rhegmatogenous retinal detachment after LASIK for myopia of up to -10 diopters: 10 years of followup. Graefes Arch Clin Exp Ophthalmol. 2012;250(7):963-70.

7. Ruiz-Moreno JM, Pérez-Santonja JJ, Alió JL. Retinal detachment in myopic eyes after laser in situ keratomileusis. Am J Ophthalmol. 1999;128:588.

8. Ruiz-Moreno JM, Alió JL. Incidence of retinal disease following refractive surgery in 9,239 eyes. J Refract Surg. 2003;19(5):534-47.

9. Daftarian N, Dehghan MH, Ahmadieh H, Soheilian M, Karkhaneh R, Lashay A Mirshahi A, Parhizkar H, Kazemimoghadam M, Modarreszadeh M, Hashemi M, Fadaei M, Entezari M. Characteristics and surgical outcomes of rhegmatogenous retinal detachment following myopic LASIK. J Ophthalmic Vis Res. 2009;4(3):151-9.

10. Hernáez-Ortega MC, Soto-Pedre E. Bilateral retinal detachment associated with giant retinal tear following LASIK. J Refract Surg. 2003;19:611.

11. Arevalo JF, Ramirez E, Suarez E, Morales-Stopello J, Cortez R, Ramirez G, et al. Incidence of vitreoretinal pathologic conditions 24 months after laser in situ ketatomileusis. Ophthalmology. 2000;107:258-62.

12. Arevalo JF, Ramires E, Suarez E, Antzoulatos G, Torres F, Cortez R, et al. Rhegmatogenous retinal detachment after laser- assisted in situ keratomileusis (LASIK) for the correction of myopia. Retina. 2000;20:338-41.

13. Arevalo JF, Ramirez E, Suarez E, Cortez R, Antzoulatos G, Morales-Stopello J, et al. Rhegmatogenous retinal detachment in myopic eyes after laser in situ keratomileusis. Frequency, characteristics, and mechanism. J Cataract Refract Surg. 2001;27:674-80.

14. Arevalo JF, Ramirez E, Suarez E, Cortez R, Ramirez G, Yepez JB. Retinal detachment in myopic eyes after laser in situ keratomileusis. J Refract Surg. 2002;18(6):708-14

15. Spaide RF. Peripheral areas of nonperfusion in treated central retinal vein occlusion as imaged by wide-field fluorescein angiography. Retina. 2011; 3|(5):829-37.

16. Kaines A, Oliver S, Reddy S, Schwartz SD. Ultrawide angle angiography for the detection and management of diabetic retinopathy. Int Ophthalmol Clin. 2009:49(2):53-9.

17. Wessel MM, Aaker GD, Parlitsis G, Cho M, D'amico DJ, Kiss S. Ultra-wide-field angiography improves the detection and classification of diabetic retinopathy. Retina. 2012;32(4):785-91.

18. Tan CS, Heussen F, Sadda SVR. Peripheral autofluorescence and clinical findings in neovascular and non-neovascular age-related macular degeneration. Ophthalmology. 2013;120(6):1271-7.

19. Oishi A, Ogino K, Makiyama Y, Nakagawa S, Kurimoto M, Yoshimura N. Wide-field fundus autofluorescence imaging of retinitis pigmentosa. Ophthalmology. 2013;120(9):1827-34.

20. Kang KB, Wessel MM, Tong J, D'Amico DJ, Chan RV. Ultra-widefield imaging for the management of pediatric retinal diseases. J Pediatr Ophthalmol Strabismus. 2013;50(5):282-8

21. Mackenzie PJ, Russell M, Ma PE, Isbister CM, Maberle DA. Sensitivity and specificity of the optos optomap for detecting peripheral retinal lesions. Retina. 2007:27(8):1119-24.

22. Witmer MT, Cho M, Favarone G, Chan RV, D'Amico DJ, Kiss S. Ultra-widefield autofluorescence imaging in non-traumatic rhegmatogenous retinal detachment. Eye (Lond). 2012;26(9):1209-16. 